\title{
The roles of water, sanitation and hygiene in reducing schistosomiasis: a review
}

\author{
Jack ET Grimes ${ }^{1 *}$, David Croll ${ }^{2,3}$, Wendy E Harrison ${ }^{4}$, Jürg Utzinger ${ }^{2,3}$, Matthew C Freeman ${ }^{5}$ and Michael R Templeton ${ }^{1}$
}

\begin{abstract}
Schistosomiasis is a disease caused by infection with blood flukes of the genus Schistosoma. Transmission of, and exposure to, the parasite result from faecal or urinary contamination of freshwater containing intermediate host snails, and dermal contact with the same water. The World Health Assembly resolution 65.21 from May 2012 urges member states to eliminate schistosomiasis through preventive chemotherapy (i.e. periodic large-scale administration of the antischistosomal drug praziquantel to school-aged children and other high-risk groups), provision of water, sanitation and hygiene (WASH) and snail control. However, control measures focus almost exclusively on preventive chemotherapy, while only few studies made an attempt to determine the impact of upgraded access to safe water, adequate sanitation and good hygiene on schistosome transmission. We recently completed a systematic review and meta-analysis pertaining to WASH and schistosomiasis and found that people with safe water and adequate sanitation have significantly lower odds of a Schistosoma infection. Importantly though, the transmission of schistosomiasis is deeply entrenched in social-ecological systems, and hence is governed by setting-specific cultural and environmental factors that determine human behaviour and snail populations. Here, we provide a comprehensive review of the literature, which explores the transmission routes of schistosomes, particularly focussing on how these might be disrupted with WASH-related technologies and human behaviour. Additionally, future research directions in this area are highlighted.
\end{abstract}

Keywords: Behaviour, Control, Endod, Environment, Hygiene, Sanitation, Schistosomiasis, Snails, Transmission, Water

\section{Background}

It is currently estimated that more than 230 million people are infected with schistosomes [1], with an additional 500 million at risk of infection [2]. Three schistosome species comprise the majority of these infections: Schistosoma haematobium (occurs mainly in sub-Saharan Africa), S. japonicum (distribution restricted to the People's Republic of China, Indonesia and the Philippines) and S. mansoni (mainly in sub-Saharan Africa, Brazil and Caribbean islands). The first species causes urogenital schistosomiasis, and parasite eggs are released in the urine, whilst S. japonicum and S. mansoni are the causative agents of intestinal schistosomiasis, with parasite eggs released in the faeces [3,4]. Infection occurs when people contact freshwater bodies infested with cercariae released by specific intermediate host

\footnotetext{
* Correspondence: jack.grimes@imperial.ac.uk

'Department of Civil and Environmental Engineering, Imperial College

London, London SW7 2AZ, UK

Full list of author information is available at the end of the article
}

snails, which have previously been infected by miracidia released from the eggs mentioned above.

Chronic intestinal schistosomiasis is manifested by debilitating symptoms, such as hepatosplenomegaly (enlargement of the liver and spleen) [3,4]. Urogenital schistosomiasis is associated with significant bladder pathology and an increased risk of developing bladder cancer [5] and thought to exacerbate the transmission of HIV and its progression to AIDS [6]. Schistosomiasis is an aetiological factor of anaemia and malnutrition [7]. Occasionally, parasite eggs enter the central nervous system, causing symptoms such as seizures and focal neurological deficits $[3,4,8]$.

Praziquantel, a safe and efficacious antischistosomal drug, has become the key tool in the global strategy against schistosomiasis [9]. An adult schistosome's natural lifespan is estimated to be around 5 to 10 years [10], demonstrating the importance of chemotherapy. However, without improvements in environmental conditions, reinfection can occur shortly after treatment, 
necessitating periodic administration of praziquantel, once every one or two years, depending on prevalence rates [11-13]. In May 2012, the World Health Assembly (WHA) declared schistosomiasis elimination to be feasible in some member states (WHA resolution 65.21), and encouraged water, sanitation and hygiene education (WASH) as components of an integrated control and elimination strategy, on the basis that they should reduce transmission by containing schistosome eggs and reducing human water contact. Soap use related to hygiene may also have a role to play in schistosomiasis control, since soap and endod (a natural soap substitute) are toxic to cercariae, miracidia and specific freshwater snails, suggesting that their use during human water contact may protect from schistosome infection $[14,15]$.

WASH conditions are inadequate in large parts of low- and middle-income countries where schistosomiasis is endemic $[3,4,16,17]$. Hence, in recent years, the need for multisectoral and integrated approaches to the control of schistosomiasis and other neglected tropical diseases (NTDs) has been emphasised [12,18-35]. In a recent systematic review and meta-analysis of the relationship between safe water, adequate sanitation, good hygiene and schistosomiasis [36], we found that people with safe water had significantly lower odds of a Schistosoma infection, as did those with adequate sanitation. However, we did not find any studies comparing odds of infection with soap use during water contact. Moreover, considerable heterogeneities in our meta-analyses suggest that the impact of WASH on schistosomiasis is highly setting-specific, possibly depending on environmental factors such as the location of freshwater bodies and the presence of intermediate host snails, as well as social and cultural factors which govern people's water contact and contamination behaviour.

Meta-analyses of observational data have the advantage of building large sample sizes through the inclusion of many different studies. However, significant associations between WASH and schistosome infection may result from confounding by socioeconomic status (SES) and other factors. In some settings, everyone has contact with infectious water and SES is unimportant $[37,38]$. Conversely, in many other settings, people with higher SES have better WASH but are also protected from infection by virtue of having deeper health-related knowledge, better healthcare and access to treatment, and less occupational exposure to infested water [39-41]. Schmidt [42] recently discussed the difficulties inherent in assessing the impact of water and sanitation on disease, and drew attention to the lack of research on the causal pathways through which water and sanitation may impact on health. Similarly, Spear [43] has called for evaluation of environmental pathogen concentrations, in both the prediction and evaluation of risk of infection. Consideration of the schistosome life cycles presents an alternative route of addressing how WASH might impact upon transmission.

In contrast to many other water- and excreta-related diseases where improvements to water supply focus on preventing consumption of contaminated water [44], since schistosomes infect people by passing through intact skin, the success of water supply improvements in preventing schistosome infection depends on the prevention of water contact. Moreover, the parasite stages in the excreta (Schistosoma eggs that release miracidia) do not pose a direct threat to humans, being infective only to intermediate host snails, which, some weeks after infection, begin to release cercariae - the stage infective to humans. Therefore, the role of sanitation in schistosomiasis control is to prevent the contamination of freshwater with excreta, rather than to prevent the ingestion of faecal pathogens. Since the parasite stages in the excreta cannot directly infect people, hand washing following defaecation or urination will not affect schistosome transmission - instead the role of soap in schistosomiasis control is to reduce the infectivity of cercariae which might otherwise infect people during contact with freshwater, and perhaps to reduce the infectivity of miracidia, and reduce snail numbers.

Here we review behavioural, biological and experimental studies pertaining to WASH for schistosomiasis control. We also explore potential reasons for the considerable heterogeneities revealed by our previous work on the relationship between WASH on schistosome transmission [36], and review the current state of research regarding WASH for schistosomiasis control, highlighting current gaps in the literature.

\section{Schistosome life cycles and disruption with upgraded WASH}

Schistosomiasis control aims to reduce the propagation of various life cycle stages, and the schistosome life cycles differ from those of other water-related pathogens, with important ramifications for environmental control. Adult schistosomes mostly live as pairs in the perivesical (S. haematobium) or the mesenteric (S. mansoni and $S$. japonicum) venous plexus of the definitive host humans and, particularly in the case of $S$. japonicum, other mammals [45]. Female S. mansoni and S. haematobium worms produce hundreds of eggs per day, while S. japonicum females lay thousands per day $[46,47]$. More than half of these eggs are retained in the host, giving rise to inflammatory reactions, which are the cause of morbidity $[3,4,48]$. The other eggs are released in the urine or the faeces, depending on the Schistosoma species. Eggs that enter freshwater bodies hatch, and each egg releases a miracidium. In the case of a Senegalese endemic community, it was estimated that one stool 
reaching freshwater might yield around 2,500 S. mansoni miracidia [49]. The miracidium is a free-living stage that attempts to infect an intermediate host snail (Biomphalaria spp. for S. mansoni, Bulinus spp. for S. haematobium and Oncomelania spp. for S. japonicum) [3,4].

Inside the snail, the miracidium undergoes asexual reproduction, giving rise to cercariae, which are then released back into the water - around 200 per day in the case of S. haematobium, 250-600 per day in the case of S. mansoni [47], and usually around 15 but occasionally up to around 160 per day in the case of $S$. japonicum [50]. Over time, one miracidium may divide into more than 20,000 schistosome cercariae [47], demonstrating the non-linear relationship between water contamination and risk of infection. These cercariae seek out a definitive host and attempt to infect it by penetrating the skin. Inside the definitive host, they develop into schistosomula, then spend 4-6 weeks in the liver, developing further into adult schistosomes [3,4]. Adult schistosomes eventually form male-female pairs and travel to the perivesical or mesenteric venous plexus, completing the cycle.

\section{Human water contact in relation to safe water supplies}

Human contact with cercariae-infested water causes Schistosoma infection, so if such water contact could be completely prevented, then transmission of the parasite would stop. However, even if safe water supplies reduce such water contact, they may not completely prevent it. The proportion of water contact that continues with safe water supplies may vary widely between different groups of people and between settings, as a result of cultural, environmental and socioeconomic differences. Furthermore, it is not clear that the amount of water contact is necessarily the limiting factor in schistosome infections, since a host's immunity and physiology - for example skin thickness - also play a role in preventing infection. If immunity and physiology, rather than the amount of water contact, are the limiting factors in schistosome infections, then water supplies that reduce - but do not completely prevent - water contact, may have little impact on the overall transmission of schistosomiasis.

Schistosomes infect people primarily by penetrating the skin [4], although experiments with human schistosomes in monkeys [51], and S. bovis in goats [52], suggest that drinking infested water can also cause infection. Early studies found that cercariae could pass through sand filters $[53,54]$, but they are susceptible to chlorination [55], and flocculation with Moringa oleifera [56]. Cercariae are non-feeding, and hence they cannot survive for more than one or two days without infecting a definitive host. Whitfield and colleagues [57], for example, observed that both the survival and the infectivity of $S$. mansoni cercariae begins to decrease after around
10 hours in the water, with very few lasting for longer than 20 hours in the water. Water storage for 24-48 hours before use has therefore long been advocated as a way to prevent schistosome infection - even as far back as 1915 [58,59]. The production of cercariae requires the presence of snails in addition to faecal or urinary contamination, so water from 'improved' sources - as defined by the World Health Organization (WHO) and UNICEF joint monitoring programme for water supply and sanitation (JMP) [17] - could reasonably be expected to be schistosome-free. Therefore, water might be considered 'safe' in terms of schistosomiasis if it is from a source defined as improved by the JMP, or has not contained an intermediate host snail for at least 48 hours.

While safe water - as defined above - is unlikely to contain cercariae, its provision will often not prevent all human contact with infested water. In some settings, activities such as fishing, sand harvesting and car washing account for considerable occupational water contact that safe water supplies would not prevent [60-62]. Similarly, in the People's Republic of China, groups such as flood relief workers, irrigation workers, canal cleaners and tourists have suffered particularly high exposure to infested water [63,64]. In Brazil, Massara and colleagues [65] found that people who crossed streams were at significantly higher risk of $S$. mansoni infection, and thus inferred that providing water supplies would do little to interrupt transmission.

Quantification of water contact is central to the consideration of how much exposure might be prevented with safe water supplies. Some studies have used the product of area of body surface exposed to the water and duration of exposure [66-69]. Others [70-72] have weighted exposure according to the time of the day, since cercaria concentrations follow diurnal cycles, peaking around midday for S. mansoni and S. haematobium, and at night for S. japonicum [73-75]. Seasonality has also been accounted for since snail numbers, and thus the risk of infection, varies according to changes in temperature, rainfall and irrigation practices [76-80]. Tiglao and Camacho [81] found that activities such as bathing and washing farm animals, which involved little movement in the water, were the strongest predictors of $S$. japonicum infection, suggesting that movement during water contact may be another important determinant of infection.

Laundry, bathing and recreational swimming are often among the activities causing the most exposure to cercaria-infested water, while the collection of water for drinking may be relatively unimportant, often involving the immersion of small areas of body surface, for relatively short durations [60,82-90]. Furthermore, recreational swimming is often engaged in by children, while 
in many settings laundry is carried out by women, accompanied by their young children who simultaneously are exposed to cercariae and, if infected, contaminate the water with eggs in their urine or faeces [91-98]. The provision of safe and adequate facilities, such as sinks with adequate privacy and drainage for laundry and bathing, and safe areas for recreational swimming, is therefore key to the prevention of Schistosoma infections in children. Where such facilities are not available, or safe water is scarce, it may be used for drinking and cooking but laundry and bathing may continue to cause contact with infested water $[99,100]$. In Nigeria, Akogun [101] found that the ratio of people to wells in four rural communities was significantly associated with the S. mansoni and S. haematobium prevalences. Data from the Gezira-Managil irrigation scheme in Sudan, and Riche Fond in St. Lucia, showed that as the amount of safe water consumed per capita increased, S. mansoni prevalence decreased, until a per capita consumption of about $70 \mathrm{l} /$ day, after which it levelled off, apparently due to residual agricultural and recreational water contact that the water supplies could not prevent [102].

'Comprehensive' water supplies - those that include facilities such as washing sinks, showers and even swimming pools, have shown success in removing laundry, bathing and recreational swimming from schistosome transmission sites. Pitchford, in a series of studies conducted in South Africa in the late 1960s, investigated the effect of providing swimming pools, water supplies, sanitation, fencing along water bodies and chemotherapy with hycanthone and ambilhar [103-105]. The prevalences of both $S$. haematobium and S. mansoni gradually decreased over the following nine years. Jordan and colleagues, in St. Lucia in the 1990s, investigated the provision of water supplies, including swimming pools for recreation, showers and laundry units [106-109]. The intervention area had a significantly lower incidence of S. mansoni infection than a comparison area supplied with standpipes only, a result attributed to the continued use of river water for washing clothes there. More recently, Kosinski et al. $[110,111]$ investigated the impact of a water recreation area on S. haematobium infection in Ghana. A significant reduction in the incidence of infection among local schoolchildren demonstrated the potential of swimming pools to prevent reinfection following preventive chemotherapy.

Elsewhere, though, safe water supplies have not been used, even for those activities to which they seem best suited - and these activities have therefore continued to cause contact with infested river water. The principle underlying reasons appear to be (i) long distances to and (ii) overcrowding at safe water sources such as boreholes and standpipes [112-114]. Other important factors include (iii) a lack of privacy at such sources - which is especially important when considering bathing; (iv) the higher chemical hardness of groundwater, as a result of which more soap is needed for washing; (v) a preference for the flavour of river water; and (vi) the opportunities for social interaction during washing afforded by rivers, in contrast to the case whereby water is collected from a safe source and the washing takes place at home [86,91,115-121]. Additionally, faulty boreholes can leak oil into the water, staining clothes and causing future water contact as people return to washing their clothes in the river [122]. Local superstitions promote contact with infested water in some settings - flowing water is sometimes regarded as cleaner [123] or as 'life-giving' [117]. However, other local factors, such as the fear of crocodiles and hippopotamuses, may reduce water contact $[124,125]$, as may the rainy season in some settings - by increasing the availability of water at home, and by rendering river water muddy [126].

In order to cause schistosomiasis, cercariae must both encounter human hosts, as a result of the latter's contact with infested water, and evade those hosts' immunological and physiological defences, as is demonstrated in Figure 1 . The debate over water contact versus immunology and physiology or exposed populations, as the limiting factor in human schistosome infections, remains unresolved and has been summarised by Wilkins et al. [127], Anderson [128] and Seto et al. [129]. If water contact is the key determinant of infection intensity, then water supply improvements might have an impact on infection intensity roughly in proportion to the amount of water contact that they prevent. However, if immunological and physiological factors such as skin thickness are stronger determinants of infection [130], then high infection rates might persist given reduced but sustained human water contact.

In St. Lucia, each age group's proportion of all water contacts observed, mirrored their proportion of the total S. mansoni infections [131]. Similarly, in Ghana, Dalton and Pole [132] found that the amount of water contact was more important than age in determining S. haematobium infection, suggesting that amount of water contact was the most important determinant. The association between amount of water contact and infection has also been found in other studies [70,133-139]. Furthermore, global positioning system (GPS)-assessed water contact frequency in mothers and young children has been found to be associated with $S$. mansoni reinfection at six months after baseline, although not with infection status at baseline [140], and water contact weighted by cercarial risk to be a significant predictor of $S$. japonicum infection even when water contact alone is not [129]. However, in some cases, the amount of time spent near water bodies may be a poor indicator of dermal contact with that water. In Ethiopia, Polderman 


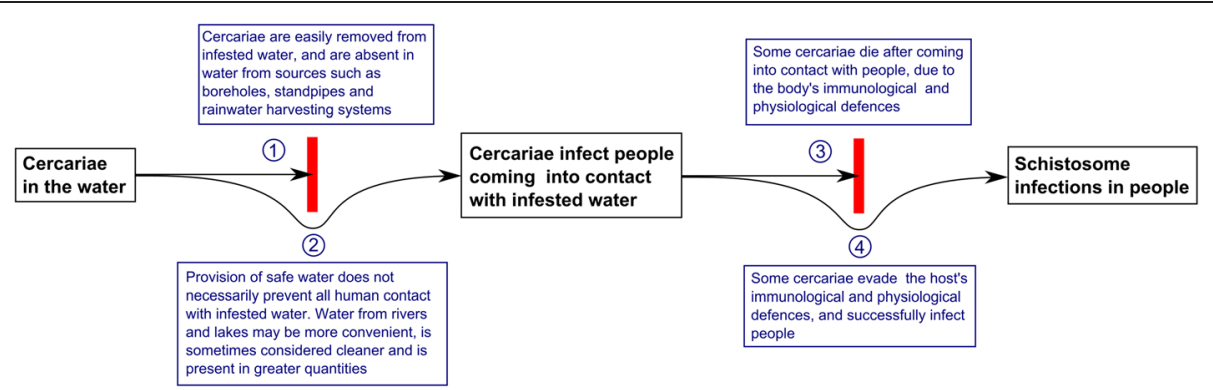

Figure 1 Flow diagram demonstrating the roles of human water contact, and immunological and physiological factors, in determining schistosome infections. Point 1 demonstrates that since water from safe sources should be free of cercariae, provision of such water should prevent schistosome infections. However, as shown at point 2, the provision of safe water often does not prevent all contact with infested water. Point 3 shows another barrier to schistosome infections, namely the host's immune system and physiology, which may kill invading cercariae before they can develop into adult schistosomes and cause pathology. Despite the host's immunological and physiological defences, some cercariae successfully develop into adult worms (point 4). The relative importance of the water contact versus immunology and physiology, in preventing schistosome infections, is poorly understood.

[141] reported that some women scooping water at a river were able to do so keeping their hands entirely dry, and demonstrated that contact with water carried home from the water body may also pose a risk of infection.

Some studies suggest that age and acquired immunity may be a more important determinant of infection than degree of exposure [61,72,142-148]. The important role of immunity in schistosome infection was emphasised by Woolhouse et al. [149], who estimated that fewer than one in a hundred contacts with infested water results in infection with S. haematobium, and fewer than one in a thousand results in egg output.

While it is known that schistosome infections occur during contact with infested water, and that some contact with such water may result from inadequate access to safe water supplies, neither the amount of water contact that might be prevented through the provision of safe water, nor the impact of such a reduction in water contact on human infection rates, are well understood. Future research should quantify the impacts of water supplies on water contact arising from various activities, in people of different ages, genders and occupations, and in different settings. It should also continue to use observational studies to investigate the relationship between human water contact and intensity of infection. This knowledge would allow the improved parameterisation of computer models, to determine the expected impacts of various kinds of water supply on schistosome infection in different groups of people. Operational research to monitor infection rates following chemotherapy and provision of different kinds of water supply infrastructure, including elements such as sinks and showers to allow people to use safe water for water-contact activities such as laundry and bathing would provide another method of exploring which forms of water supply can interrupt schistosome transmission, and which other social and behavioural factors affect their effectiveness - as discussed above, this has already been done for a water recreation area [111].

\section{Sanitation to contain miracidia and prevent snail infections}

Schistosomiasis transmission might be expected to be amenable to control through adequate sanitation - defined as infrastructure that contains excreta since the parasite eggs leave the definitive host in the urine or faeces. By preventing eggs in the excreta from entering freshwater bodies inhabited by intermediate host snails, sanitation should prevent snail infections. A reduction in snail infections, in turn, might be expected to reduce the concentration of cercariae, and hence, the risk of human infection. Miracidia in latrine pits or sewerage systems cannot infect intermediate host snails. However, hygienic bathing and reservoir hosts might provide another source of miracidia in transmission sites, and it is not clear that input of eggs into freshwater is necessarily a limiting factor in schistosome transmission snail populations and the degree of human water contact may be more important. A given reduction in miracidia does not lead to a proportional reduction in cercariae and human infections, owing to the exponential reproduction of the parasite within the intermediate host snail. More complexity arises from the detrimental effects of schistosome infections on the snails, rendering theoretical predictions of the impact of sanitation on schistosome transmission extremely difficult. 
Sanitation systems adequate for schistosomiasis control align with those considered 'improved' by the JMP [17], which includes any facility that hygienically separates human waste from human contact. Maldonado and colleagues, in the late 1940s, investigated the survival and hatchability of $S$. mansoni eggs in different environments, as well as the infectivity of miracidia released at different times [150,151]. In a latrine pit, more than $70 \%$ of eggs were found to hatch during their first eight hours in water. In a separate experiment, no miracidium was found to survive for longer than nine hours in the water. Kawata and Kruse [152] found similar survival times for S. mansoni miracidia in sewage stabilization ponds. Biogas digesters have been found inhospitable to schistosome miracidia, with less than $1 \%$ of $S$. japonicum eggs viable after two months [153], a reduction explained as being due to a combination of sedimentation and biochemical inactivation. Thus urine and faeces in adequate sanitation systems are rendered safe in terms of schistosomiasis after relatively short periods of time, while it takes longer for other helminths such as Ascaris lumbricoides and Trichuris trichiura [154,155]. Sewage sludge would have to run into water bodies containing snails within a few days in order to sustain transmission, and while latrines do sometimes drain directly into water bodies [156], such systems are not considered improved according to JMP guidelines [17].

The presence of adequate sanitation does not necessarily guarantee its use, particularly for urination [5]. Indeed, the bulk of $S$. haematobium eggs reaching freshwater are thought to stem from urination directly into the water, largely by children during bathing and swimming [157]. Open water bodies may be particularly attractive sites for open defaecation and urination, often by men $[60,99]$, for two more reasons: the availability of water for washing following defaecation and the privacy afforded by vegetation, which might be absent elsewhere in the area [158]. In Sudan, privacy was found to be more important than the presence of water for washing $[159,160]$, and this observation was confirmed in subsequent studies in Nigeria and Senegal [161,162]. Such practices vary according to local attitudes: in Brazil and in Ethiopia, people were found to avoid defecating into or near open water bodies which were used for drinking water and bathing [134,141].

Faeces need not enter the water immediately to sustain transmission - those left near water bodies may be washed in during rain or flooding of the river banks, or may be trodden into the river by people or animals $[157,158,163]$. Eggs of different schistosome species have different longevities - S. mansoni can survive for up to about eight days out of the water, while $S$. japonicum eggs may survive for several weeks $[151,164]$.
Even if people always use adequate sanitation, it is possible that viable eggs may wash off from the body or from soiled clothing, into the water $[141,157,158,165,166]$. In Senegal, it was found that hygienic bathing (washing in the river following defaecation) can put significant numbers of schistosome eggs into the water; hygienic bathing by 991 people was found to be equivalent to 12 people defecating directly into the water [49]. Since infection usually occurs outside of the household [71,132], an individual's risk is therefore determined not just by his or her family's sanitary practices but by those of the whole community.

In addition to eggs that enter water bodies due to a lack of sanitation coverage or use, more may be provided by reservoir hosts. S. japonicum has many animal reservoir hosts, which are understood to contribute significantly to transmission [45,167]. In particular, water buffaloes are often found highly infected $[168,169]$, and in one Chinese village, Wang et al. [170] found water buffaloes to account for over $90 \%$ of S. japonicum egg output. Elsewhere in the People's Republic of China, combining human chemotherapy with that of bovines has been shown to reduce reinfection in people [171]. Animals may even promote transmission without actually being infected; Wang et al. [172] demonstrated that uninfected chickens and dogs may pass viable $S$. japonicum eggs after eating the faeces of an infected host.

For S. mansoni and S. haematobium, however, there is less evidence for important reservoir hosts. Baboons [173-176], chimpanzees [177] and water rats [178-184] have been found naturally infected with $S$. mansoni, and able to pass viable eggs. However, since these were usually around areas of heavy human infection, they are taken as being the result, rather than the cause, of human infection [47]. Primates, pigs, sheep, rodents, monkeys and sea lions have been found naturally infected with $S$. haematobium, but these are thought to be isolated discoveries of limited importance in schistosomiasis transmission $[47,185]$. Figure 2 shows how the barrier imposed by adequate sanitation may be circumvented by the non-use of the sanitation, eggs washing off the body or clothes of humans, and reservoir hosts.

Macdonald [186], in his early model of the dynamics of schistosomiasis transmission, predicted that even very high levels of sanitation would not have any impact on infection rates. This prediction rested upon the idea that the number of miracidia is not a limiting factor in schistosome transmission - few are needed to maintain snail infections, which give rise to the release of many cercariae, and therefore contamination of water bodies with excreta would have to be reduced to a tiny 


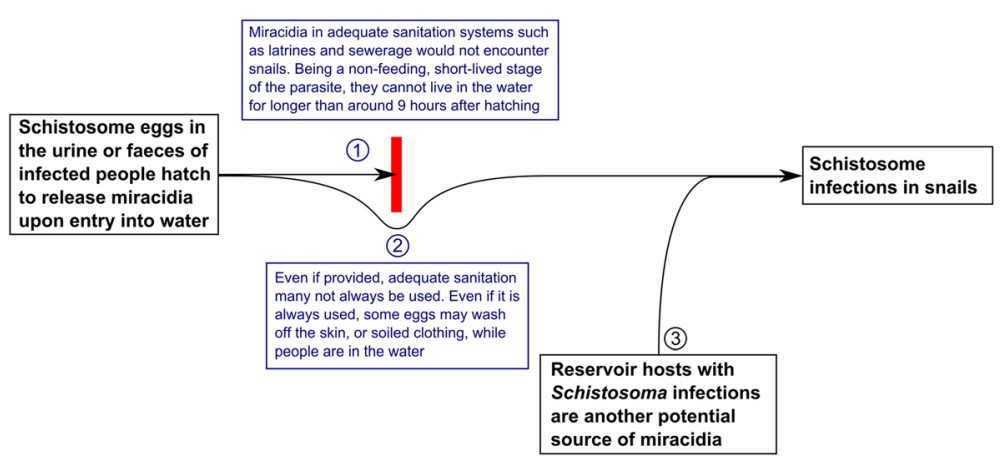

Figure 2 Flow diagram demonstrating how schistosome transmission may persist despite the use of adequate sanitation. Schistosome eggs hatch upon entry into freshwater, and release miracida. These miracidia cannot survive for long without infecting an intermediate host, so miracidia in adequate sanitation systems are unlikely to contribute to transmission (point 1). However, it is possible that some eggs may enter freshwater as a result of washing off the bodies or soiled clothing of those infected (point 2). Reservoir hosts provide another potential source of miracidia (point 3).

proportion in order to significantly reduce the force of transmission [186]. Later on, other scientists questioned the general validity of this claim, which was strongly dependent on model parameters and assumptions $[187,188]$. However, there is consensus that prevention of water contamination would be a less effective control measure than the prevention of human water contact, since, as a result of this reproduction within the snail, many cercariae will continue to be released, even if the number of miracidia in the water is reduced.

As shown in Figure 3, high organic pollution of a water body may limit the habitats of intermediate host snails, which thrive under mild organic pollution, but are rarely found in areas of heavy pollution [47,189-195]. Sanitation, which acts to reduce such organic pollution, may therefore expand such habitats. With more snails present, the probability of a miracidium finding and infecting a snail is higher [196], and therefore under certain circumstances, sanitation might increase cercaria numbers.
The relationship between sanitation and cercarial density is further complicated by the complex interactions between snail schistosome infections, longevity and thus density, and cercarial production. S. mansoni and S. japonicum infections have been found to increase snail mortality and reduce fecundity [197-199]; effects that are suggested to be more acute in areas of high snail density, due to increased competition for resources [200]. Furthermore, snails infected with many miracidia have been found to yield fewer cercariae than those infected with just one miracidium; an effect referred to as "sporocyst crowding" [197,201]. A computer model developed by Mangal and colleagues [202] predicted that under certain conditions, sanitation might actually exacerbate transmission, as a result of reduced miracidial infection increasing the average snail lifespan and thus the density of snails, all of which nevertheless remain infected by the few miracidia that enter the water even with better sanitation. On the other hand, Sandbach [203] draws attention to the low prevalences of snail

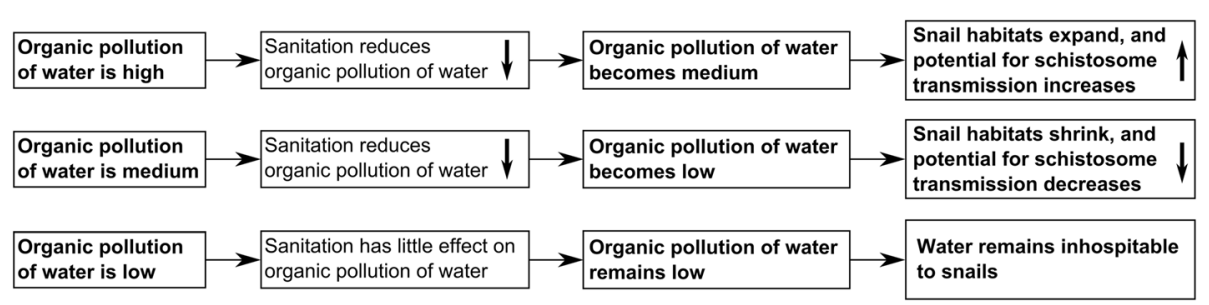

Figure 3 Flow diagram demonstrating how sanitation may increase or decrease snail numbers, depending on the organic pollution of the water. By containing excreta, and keeping it away from water bodies, sanitation will reduce organic pollution. However, this may be either detrimental, or under certain circumstances, beneficial to intermediate host snails, that thrive under conditions of mild (but not low or high) organic pollution. 
infections found even in areas of high human infection rates. From this, the author inferred that schistosomiasis transmission dynamics are much more sensitive to the input of eggs into the water than they are to snail population densities, implying that sanitation might be more effective than snail control. The opposing effects of a reduction in miracidia, on the number of cercariae, is shown in Figure 4.

The JMP measures water and sanitation access in households, and mentions increased access to improved water and sanitation in schools and health centres as key targets [17]. However, there is no mention of improving sanitation in other locations, such as fields and water contact sites, which are perhaps seen as a lower priority. In Zimbabwe, Chimbari et al. [122] demonstrated that people working in the fields will not travel long distances to use their household latrines. Raw sewage is often used to fertilise crops, particularly in Asia [204], and this practice has sometimes been found to be associated with a greater risk of schistosome infection [205].

It is well understood that eggs in latrine pits mostly do not contribute to schistosome transmission, but that eggs may also enter the water despite the use of latrines. Research is needed to quantify the reductions in miracidial contamination of water bodies that sanitation may achieve - and computer models should determine whether these might be sufficient to make this part of the life cycle a limiting factor. As with water supplies, operational studies should monitor infection rates following chemotherapy and the improvement of sanitation. For example, randomised controlled trials could test latrine provision in different settings, in particular in fields and as close as practically possible to transmission sites. Reservoir hosts represent a possible source of miracidia that cannot be controlled through sanitation, and studies are needed to quantify the number of $S$. mansoni and S. haematobium eggs that they contribute to transmission sites, in order to determine their importance for transmission once human infection rates fall. Moreover, it should be determined whether sanitation provision or reservoir host control might be a more cost-effective method of reducing the input of miracidia into freshwater bodies.
Soap use during water contact to control cercariae, snails and miracidia

In addition to water supplies and sanitation, one aspect of hygiene - the use of soap or endod (a natural soap substitute) during water contact - may play a role in schistosomiasis control, due to the demonstrated toxicities of soap and endod towards various schistosome life cycle stages. Detergents are understood to be toxic to cercariae of S. mansoni [206,207], S. mattheei [208] and also to Biomphalaria glabrata, the intermediate host snail of S. mansoni in Latin America [209]. Okwuosa and Osuala [14] tested the protective effects of different concentrations of washing soaps, on mice immersed in water containing $S$. mansoni cercariae, and found that even at sub-lethal concentrations, these soaps suppressed the infectivity of cercariae.

Many plants have molluscicidal poperties, but endod (Phytolacca dodecandra, or soapberry) is of particular interest here since it also has a hygienic use - it is sometimes employed for washing clothes [210]. Its toxicity to snails, and at lower concentrations, to miracidia and cercariae, is the result of a saponin named 'lemmatoxin' [15,211-213]. As with soap, sub-lethal doses of endod reduce the infectivity of schistosome larvae.

In view of these findings, the use of soap or endod in the washing of clothes might confer some protection both immediately, by killing or reducing the infectivity of cercariae which would otherwise infect people washing clothes in environmental water bodies, but also in the long term, by killing snails and miracidia, and by reducing the infectivity of miracidia. Indeed, some studies have accounted for soap use, which may explain lower infection rates than would be expected based purely on the amount of water contact [71,214-216]. In Zanzibar, Rudge et al. [215] found that washing clothes was not significantly associated with a higher risk of $S$. haematobium infection, possibly due to the protective effects of soap which was widely used in this setting. However, Garba et al. [94] found that the use of soap during bathing did not appear to protect infants from schistosomiasis, and suggested that this was due to the long bathing times involved.

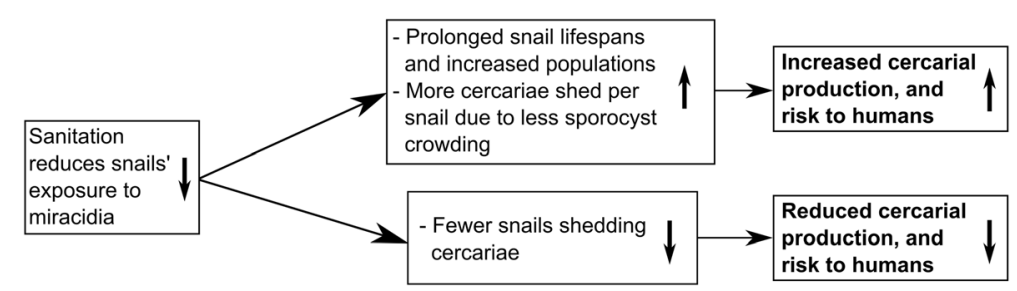

Figure 4 Flow diagram demonstrating how sanitation may increase or decrease cercarial production depending on the setting. Reducing snails' exposure to miracidia may reduce the number of snails infected and shedding cercariae, or under certain circumstances, by reducing the number of miracidia infecting each snail, it may increase snail longevity and cercarial output. Which effect is stronger depends on how frequently snails encounter miracidia, which varies between settings. 
Erko et al. [217], in Ethiopia, investigated different methods of application of endod to water bodies. In a town using endod soap, the prevalence among males rose slightly (the difference was not statistically significant), while the prevalence among females dropped significantly [217]. This may have been due to women and girls being more likely to have water contact during activities such as washing clothes, which involve the use of soap.

As with water and sanitation, past studies have informed the rationale for schistosomiasis control through soap and endod use during water contact, but only Erko et al. [217] have performed a trial to investigate the impact on human infection rates. Quantification of the impacts of such hygiene promotion on snail, miracidium and cercaria populations, would enable researchers to specifically parameterise computer models to determine whether the use of soap or endod can give rise to a limiting factor in schistosome transmission. Such models, in turn, could quantify the impact of specific hygiene promotion on the risk of infection in (i) participants using soap or endod, which might protect them by killing cercaria or otherwise rendering them uninfective and in (ii) other people coming into contact with the water, whose risk of infection might be lowered as a result of reductions in snail and miracidium populations.
As with water and sanitation, further intervention studies could test any impact directly, through the assessment of the rapidity of reinfection following chemotherapy. Clearly schistosomiasis control using soap or endod is heavily dependent on human behaviour in addition to the dynamics of schistosome transmission. It would therefore be beneficial for these studies to include social and behavioural components to investigate the acceptability of soap use during water contact in different settings, along with whether health education can increase soap use during human water contact in the long term.

\section{Summary of evidence regarding the roles of WASH in schistosomiasis control}

There are good reasons to believe that improvements in WASH should, in general, reduce the force of schistosomiasis transmission, even if their impacts are highly dependent on the social-ecological context, due to a combination of behavioural, biological, cultural, demographic, ecological, environmental and socioeconomic factors $[36,218]$. However, the pathways prevented by WASH technologies and human behaviours differ for schistosomiasis as compared to other enteric diseases. Reductions in different parts of the schistosome life cycle (such as contamination of freshwater with

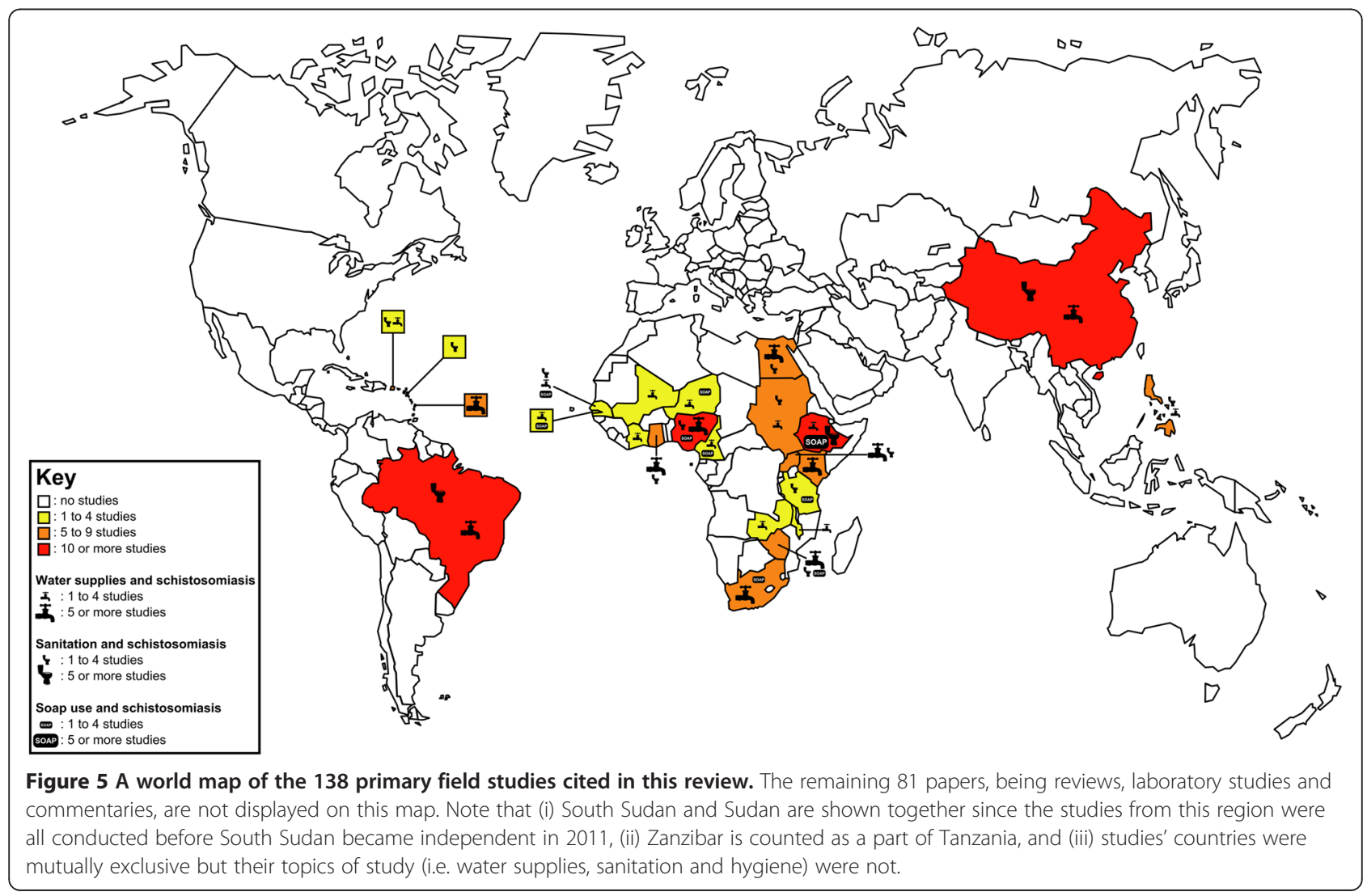


miracidia, and human exposure to cercaria-infested water) will only affect schistosome transmission if the part in question is, or becomes, the limiting factor - and which is the limiting factor in schistosome transmission will likely vary from one setting to another.

Qualitative reviews can complement systematic reviews and meta-analyses by exploring heterogeneities in the risk of infection with Schistosoma and other causative agents of NTDs, depending on the prevailing social-ecological systems. It is well understood that schistosomiasis transmission occurs focally, in freshwater bodies that are contaminated with human faeces or urine, that are inhabited by specific intermediate host snails and where human water contact patterns occur. However, schistosomiasis control is currently focused on killing the adult worms in the human body through periodic administration of praziquantel, while only token attention is given to the underlying ecology, which includes complex relationships between people's behaviour, the parasites and intermediate host snails. As shown in Figure 5, many studies across schistosomeendemic parts of the world inform the potential roles that WASH might play in schistosomiasis control and elimination.

\section{Conclusions}

While much is known about the impact of WASH on schistosomiasis, many questions remain. The evidence for specific aspects of water, sanitation and hygiene behaviour reducing schistosome transmission is summarised in

Table 1 Summary of the key points regarding water, sanitation and hygiene for schistosomiasis control, and suggested directions for future research

\begin{tabular}{lll}
\hline Domain & Summary points & Open research questions \\
\hline Water & - Water from safe supplies is usually schistosome-free, and hence it & • Do communities provided with safe water supplies experience \\
& may play an important role in reducing exposure & $\begin{array}{l}\text { slower reinfection (lower intensities of infection at set points in } \\
\text { time following preventive chemotherapy)? }\end{array}$
\end{tabular}

- People's motivations for water contact are highly context-dependent, and water supplies that do not account for local attitudes and practices cannot be expected to consistently reduce water contact

- How do different types of water supply infrastructure (e.g. household and community supplies, with and without sinks and showers) affect the amount of exposure to cercaria-infested water in different groups of people (preschool-aged children, school-aged children, adults, males, females and people in communities of different religions and engaged in different forms of water contact)?

- Where possible, water supplies should incorporate additional infrastructure such as sinks and showers, to prevent as much water contact as possible

- How do reductions in water contact affect the intensity of schistosome infection in different groups of people (preschool-aged children, school-aged children, adults, males, females, those from or

- The relationships between people's access to safe water supplies not from endemic communities)? and their degree of water contact, and between their degree of water contact and their intensity of infection, are not well understood

Sanitation • Eggs in latrine pits cannot sustain schistosome transmission, but eggs may still enter the water despite the use of adequate sanitation

- Do communities provided with adequate sanitation experience slower reinfection (lower intensities of infection at set points in time following preventive chemotherapy)?

- High levels of organic pollution, and infection with schistosome sporocysts, are detrimental to intermediate host snails, and therefore the impact on cercaria populations, of a reduction in miracidial contamination, is very difficult to predict

- By contaminating freshwater bodies with schistosome eggs in their faeces and urine, reservoir hosts play an important role in S. japonicum transmission, and may also play a role in S. mansoni and S. haematobium transmission

Hygiene - Soap and endod are toxic to miracidia, cercariae and intermediate host snails - they may therefore reduce risk of infection in the short term, by killing and reducing the infectivity of cercariae, and in the long term, by killing snails and miracidia, and thus reducing cercaria populations

- Is sanitation in fields and near transmission sites effective at reducing the number of miracidia at those transmission sites?

- Very few studies have compared human use of soap or endod during water contact, with subsequent schistosome infections

- How does the number of snails affect the relationship between the numbers of miracidia and cercariae at transmission sites?

- What role do reservoir hosts play in the transmission of S. mansoni and S. haematobium?

- Does sustained soap use during water contact slow reinfection (lower intensities of infection at set points in time following preventive chemotherapy)?

- What impact does sustained soap use have on snail, miracidium and cercaria populations?

- Does protection from infection arising from soap use extend to people not using the soap, by virtue of the impacts on snail populations and miracidial infections?

- How might soap use during human water contact be best promoted? 
Table 1, along with questions that future research might address.

The ability of water supplies to prevent water contact depends on the local activities involving water contact, convenience, the chemical composition of water and local beliefs and superstitions. Although schistosome infection certainly occurs during water contact, it is difficult to predict the impact of a reduction in water contact on infection, due to the effects of age-acquired immunity.

Access to, and use of, adequate sanitation will catch most Schistosoma eggs and prevent miracidia from infecting intermediate host snails. However, sustained transmission requires only a few eggs to enter freshwater, and these do so without people defaecating or urinating into the water. Organic pollution of water bodies, and schistosome infections, can be detrimental to snails, and therefore under certain circumstances, sanitation may exacerbate the transmission of schistosomiasis. Reductions in the input of eggs into freshwater may have no impact if this is not a limiting factor in overall transmission.

The use of soap, detergent and endod during water contact appears to confer some protection from infection, depending on the duration of water contact. However, little is known about the quantitative impact on risk of infection among people engaging in such water contact.

Preventive chemotherapy using the existing education system is inexpensive, by some estimates, less than US\$ 0.50 per child per year [219]. However, this results from the economies of scale, which allow for the treatment of many children in one deworming campaign. As countries push towards elimination of schistosomiasis, infection rates will fall, and the cost per person in need of treatment (i.e. those who are infected) will rise. Suitable improvements in WASH may then be particularly beneficial in tackling refractory transmission foci by preventing reinfection following chemotherapy. Such WASH interventions should take account of the many local factors and social-economic contexts that will determine their effectiveness.

\footnotetext{
Abbreviations

AIDS: Acquired immune deficiency syndrome; GPS: Global Positioning System; HIV: Human immunodeficiency virus; JMP: The WHO and UNICEF joint monitoring programme for water supply and sanitation; NTDs: Neglected tropical diseases; SES: Socioeconomic status; UNICEF: the United Nations Children's Fund; WASH: Water, sanitation and hygiene; WHA: World Health Assembly; WHO: World Health Organization.
}

\section{Competing interests}

The authors declare that they have no competing interests.

\section{Authors' contributions}

This work was carried out primarily by JETG as part of a PhD project, supervised by MRT and WEH. JETG, MRT and WEH developed the protocol. JETG carried out the literature searches and JETG and DC screened the literature, and identified the relevant studies. JETG, WEH and MRT prepared the first draft of the manuscript. All authors contributed to further revisions, and read and met the ICMJE criteria for authorship. All authors read and approved the final manuscript.

\section{Acknowledgements}

We are grateful to the librarians at Imperial College London, Swiss Tropical and Public Health Institute, the London School of Hygiene and Tropical Medicine, the British Library and the Wellcome Library for their help in obtaining so many relevant references. We also thank Mr. Wei Qiu, Dr. Peiling Yap and Ms. Yingsi Lai for their help in translating and interpreting the Chinese papers, Dr. Susana Almeida for her help with the papers in Portuguese, and Dr. Mirko S. Winkler for his helpful suggestions regarding Figure 5.

\section{Author details}

'Department of Civil and Environmental Engineering, Imperial College London, London SW7 2AZ, UK. '2Department of Epidemiology and Public Health, Swiss Tropical and Public Health Institute, P.O. Box, CH-4002 Basel, Switzerland. ${ }^{3}$ University of Basel, P.O. Box, CH-4003 Basel, Switzerland. ${ }^{4}$ Schistosomiasis Control Initiative, Imperial College London, London SW7 2AZ, UK. ${ }^{5}$ Department of Environmental Health, Rollins School of Public Health, Emory University, Atlanta, GA 30322, USA.

Received: 12 December 2014 Accepted: 18 February 2015

Published online: 13 March 2015

\section{References}

1. Vos T, Flaxman AD, Naghavi M, Lozano R, Michaud C, Ezzati M, et al. Years lived with disability (YLDs) for 1160 sequelae of 289 diseases and injuries 1990-2010: a systematic analysis for the Global Burden of Disease Study 2010. Lancet. 2012;380:2163-96.

2. Steinmann P, Keiser J, Bos R, Tanner M, Utzinger J. Schistosomiasis and water resources development: systematic review, meta-analysis, and estimates of people at risk. Lancet Infect Dis. 2006;6:411-25.

3. Gryseels B, Polman K, Clerinx J, Kestens L. Human schistosomiasis. Lancet. 2006:368:1106-18.

4. Colley DG, Bustinduy AL, Secor WE, King CH. Human schistosomiasis. Lancet 2014;383:2253-64

5. Rollinson D. A wake up call for urinary schistosomiasis: reconciling research effort with public health importance. Parasitology. 2009;136:1593-610.

6. Secor WE. The effects of schistosomiasis on HIV/AIDS infection, progression and transmission. Curr Opin HIV AIDS. 2012;7:254-9.

7. King CH, Dickman K, Tisch DJ. Reassessment of the cost of chronic helmintic infection: a meta-analysis of disability-related outcomes in endemic schistosomiasis. Lancet. 2005;365:1561-9.

8. Ferrari TC, Moreira PR. Neuroschistosomiasis: clinical symptoms and pathogenesis. Lancet Neurol. 2011;10:853-64.

9. Doenhoff MJ, Cioli D, Utzinger J. Praziquantel: mechanisms of action, resistance and new derivatives for schistosomiasis. Curr Opin Infect Dis. 2008;21:659-67.

10. Fulford AJ, Butterworth AE, Ouma JH, Sturrock RF. A statistical approach to schistosome population dynamics and estimation of the life-span of Schistosoma mansoni in man. Parasitology. 1995;110:307-16.

11. Bruun B, Aagaard-Hansen J. The social context of schistosomiasis and its control: an introduction and annotated bibliography. Geneva: World Health Organization; 2008

12. Utzinger J, Raso G, Brooker S, de Savigny D, Tanner M, Ørnbjerg N, et al. Schistosomiasis and neglected tropical diseases: towards integrated and sustainable control and a word of caution. Parasitology. 2009;136:1859-74.

13. WHO. Helminth control in school-age children: a guide for managers of control programmes (second edition). Geneva: World Health Organization; 2011.

14. Okwuosa VN, Osuala FO. Toxicity of washing soaps to Schistosoma mansoni cercariae and effects of sublethal concentrations on infectivity in mice. Appl Parasitol. 1993;34:69-75.

15. Birrie H, Balcha F, Erko B, Bezuneh A, Gemeda N. Investigation into the cercariacidal and miracidiacidal properties of endod (Phytolacca dodecandra) berries (type 44). East Afr Med J. 1998;75:311-4.

16. Pullan RL, Freeman MC, Gething PW, Brooker SJ. Geographical inequalities in use of improved drinking water supply and sanitation across sub-Saharan Africa: mapping and spatial analysis of cross-sectional survey data. PLoS Med. 2014;11:e1001626. 
17. WHO, UNICEF. Progress on drinking water and sanitation - 2014 update. Geneva: World Health Organization; 2014.

18. Huang Y, Manderson L. Schistosomiasis and the social patterning of infection. Acta Trop. 1992;51:175-94.

19. Hunter JM, Rey L, Chu K, Adekolu-John E, Mott KE. Parasitic diseases in water resources development: the need for intersectoral negotiation. Geneva: World Health Organization; 1993.

20. Evans AC, Stephenson LS. Not by drugs alone: the fight against parasitic helminths. World Health Forum. 1995;16:258-61.

21. Utzinger J, Bergquist $\mathrm{R}$, Xiao SH, Singer BH, Tanner M. Sustainable schistosomiasis control - the way forward. Lancet. 2003;362:1932-4.

22. Huang $Y X$, Manderson L. The social and economic context and determinants of schistosomiasis japonica. Acta Trop. 2005;96:223-31.

23. Singer $\mathrm{BH}$, de Castro MC. Bridges to sustainable tropical health. Proc Natl Acad Sci U S A. 2007;104:16038-43.

24. Spiegel JM, Dharamsi S, Wasan KM, Yassi A, Singer B, Hotez PJ, et al. Which new approaches to tackling neglected tropical diseases show promise? PLoS Med. 2010;7:e1000255.

25. Utzinger J, N'Goran EK, Caffrey CR, Keiser J. From innovation to application: social-ecological context, diagnostics, drugs and integrated control of schistosomiasis. Acta Trop. 2011;120 Suppl 1:S121-37.

26. Anonymous. Progress in sanitation needed for neglected tropical diseases. Lancet. 2012;379:978.

27. Gazzinelli A, Correa-Oliveira R, Yang GJ, Boatin BA, Kloos H. A research agenda for helminth diseases of humans: social ecology, environmental determinants, and health systems. PLoS Negl Trop Dis. 2012;6:e1603.

28. Prichard RK, Basáñez MG, Boatin BA, McCarthy JS, Garcia HH, Yang GJ, et al. A research agenda for helminth diseases of humans: intervention for control and elimination. PLoS Negl Trop Dis. 2012;6:e1549.

29. Bockarie MJ, Kelly-Hope LA, Rebollo M, Molyneux DH. Preventive chemotherapy as a strategy for elimination of neglected tropical parasitic diseases: endgame challenges. Phil Trans R Soc B. 2013;368:20120144.

30. Freeman MC, Ogden S, Jacobson J, Abbott D, Addiss DG, Amnie AG, et al. Integration of water, sanitation, and hygiene for the prevention and control of neglected tropical diseases: a rationale for inter-sectoral collaboration. PLoS Negl Trop Dis. 2013;7:e2439.

31. WHO. Sustaining the drive to overcome the global impact of neglected tropical diseases: second WHO report on neglected diseases. Geneva: World Health Organization; 2013.

32. Campbell SJ, Savage GB, Gray DJ, Atkinson J-AM, Soares Magalhães RJ, Nery SV, et al. Water, sanitation, and hygiene (WASH): a critical component for sustainable soil-transmitted helminth and schistosomiasis control. PLoS Negl Trop Dis. 2014;8:e2651.

33. Clasen T, Boisson S, Routray P, Torondel B, Bell M, Cumming O, et al. Effectiveness of a rural sanitation programme on diarrhoea, soil-transmitted helminth infection, and child malnutrition in Odisha, India: a cluster-randomised trial. Lancet Glob Health. 2014;2:e645-53.

34. Secor WE. Water-based interventions for schistosomiasis control. Pathog Glob Health. 2014;108:246-54.

35. Nakagawa J, Ehrenberg JP, Nealon J, Fürst T, Aratchige P, Gonzales G, et al. Towards effective prevention and control of helminth neglected tropical diseases in the Western Pacific Region through multi-disease and multi-sectoral interventions. Acta Trop. 2015;141:407-18.

36. Grimes JET, Croll D, Harrison WE, Utzinger J, Freeman MC, Templeton MR. The relationship between water, sanitation and schistosomiasis: a systematic review and meta-analysis. PLoS Negl Trop Dis. 2014;8:e3296.

37. Huang $Y$, Manderson L. Socioeconomic factors and prevalence of schistosomiasis japonica in a rural area of China. Chin J Schisto Control. 1999;11:137-42.

38. Gazzinelli A, Velasquez-Melendez G, Crawford SB, LoVerde PT, Correa-Oliveira R, Kloos H. Socioeconomic determinants of schistosomiasis in a poor rural area in Brazil. Acta Trop. 2006;99:260-71.

39. Farooq M, Nielsen J, Samaan SA, Mallah MB, Allam AA. The epidemiology of Schistosoma haematobium and S. mansoni infections in the Egypt-49 project area. 3. Prevalence of bilharziasis in relation to certain environmental factors. Bull World Health Organ. 1966;35:319-30.

40. Bethony J, Williams JT, Kloos H, Blangero J, Alves-Fraga L, Buck G, et al. Exposure to Schistosoma mansoni infection in a rural area in Brazil. II: Household risk factors. Trop Med Int Health. 2001;6:136-45.

41. Pullan RL, Bethony JM, Geiger SM, Cundill B, Correa-Oliveira R, Quinnell RJ, et al. Human helminth co-infection: analysis of spatial patterns and risk factors in a Brazilian community. PLoS Negl Trop Dis. 2008;2:e352.
42. Schmidt W-P. The elusive effect of water and sanitation on the global burden of disease. Trop Med Int Health. 2014;19:522-7.

43. Spear RC. Commentary by Spear, R. on "Integration of water, sanitation, and hygiene for the prevention and control of neglected tropical diseases: a rationale for inter-sectoral collaboration:" Can the control of NTDs profit from a good WASH? PLOS Negl Trop Dis. 2013;7:e2473.

44. Mara DD, Feachem RGA. Water- and excreta-related diseases: unitary environmental classification. J Environ Eng. 1999;125:334.

45. McManus DP, Gray DJ, Li Y, Feng Z, Williams GM, Stewart D, et al. Schistosomiasis in the People's Republic of China: the era of the Three Gorges Dam. Clin Microbiol Rev. 2010;23:442-66.

46. Moore DV, Sandground JH. The relative egg producing capacity of Schistosoma mansoni and Schistosoma japonicum. Am J Trop Med Hyg. 1956:5:831-40.

47. Ayad N. A short review of the epidemiology of schistosomiasis in Africa. Egypt J Bilharz. 1974;1:9-27.

48. Warren KS. The secret of the immunopathogenesis of schistosomiasis: in vivo models. Immunol Rev. 1982;61:189-213.

49. Sow S, Polman K, Vereecken K, Vercruysse J, Gryseels B, de Vlas SJ. The role of hygienic bathing after defecation in the transmission of Schistosoma mansoni. Trans R Soc Trop Med Hyg. 2008;102:542-7.

50. Jordan P, Webbe G. Schistosomiasis: epidemiology, treatment, and control. London: Heinemann; 1982.

51. Leiper RT. Report on the results of the bilharzia mission in Egypt, 1915. Part I: Transmission. J R Army Med Corps. 1915;25:1-48.

52. Boulanger D, Schneider D, Sidikou F, Capron A, Chippaux JP, Sellin B. The oral route as a potential way of transmission of Schistosoma bovis in goats. J Parasitol. 1999:85:464-7.

53. Jones MF, Brady FJ. The removal of the cercariae of Schistosoma mansoni from water by filtration through diatomaceous silica in a small model filter. Public Health Rep. 1946;61:1538-43.

54. Jones MF, Brady FJ. Effects of water treatment processes on schistosome cercariae. Bull Natl Inst Health. 1947;2:109-30.

55. Coles GC, Mann H. Schistosomiasis and water works practice in Uganda. East Afr Med J. 1971:48:40-3.

56. Olsen A. Low technology water purification by bentonite clay and Moringa oleifera seed flocculation as performed in Sudanese villages: effects on Schistosoma mansoni cercariae. Water Res. 1987;21:517-22.

57. Whitfield PJ, Bartlett A, Khammo N, Clothier RH. Age-dependent survival and infectivity of Schistosoma mansoni cercariae. Parasitology. 2003;127:29-35.

58. Leiper RT. Report on the results of the bilharzia mission in Egypt, 1915. Part II: Prevention and eradication. J R Army Med Corps. 1915;25:147-92.

59. Jordan P. From Katayama to the Dakhla Oasis: the beginning of epidemiology and control of bilharzia. Acta Trop. 2000;77:9-40.

60. Tayo MA, Pugh RN, Bradley AK. Malumfashi Endemic Diseases Research Project, XI. Water-contact activities in the schistosomiasis study area. Ann Trop Med Parasitol. 1980;74:347-54.

61. Black CL, Mwinzi PNM, Muok EMO, Abudho B, Fitzsimmons CM, Dunne DW, et al. Influence of exposure history on the immunology and development of resistance to human schistosomiasis mansoni. PLoS Negl Trop Dis. 2010;4:e637.

62. Pinot de Moira A, Fulford AJ, Kabatereine NB, Kazibwe F, Ouma JH, Dunne DW, et al. Microgeographical and tribal variations in water contact and Schistosoma mansoni exposure within a Ugandan fishing community. Trop Med Int Health. 2007;12:724-35.

63. Song $Y$, Xiao S, Wu W, Zhang $S$, Xie $H, X u X$, et al. Preventive effect of artemether on schistosome infection. Chin Med J. 1998;111:123-7.

64. Utzinger J, Xiao SH, N'Goran EK, Bergquist R, Tanner M. The potential of artemether for the control of schistosomiasis. Int J Parasitol. 2001;31:1549-62.

65. Massara CL, Peixoto SV, Da Silva BH, Enk MJ, Dos Santos CO, Schall V. Factors associated with schistosomiasis mansoni in a population from the municipality of jaboticatubas, State of Minas Gerais, Brazil. Mem Inst Oswaldo Cruz. 2004;99:127-34.

66. Ross AGP, Li YS, Sleigh AC, Williams GM, Hartel GF, Forsyth SJ, et al. Measuring exposure to $S$. japonicum in China. I. Activity diaries to assess water contact and comparison to other measures. Acta Trop. 1998;71:213-28.

67. Ross AGP, Sleigh AC, Li YS, Williams GM, Waine GJ, Forsyth SJ, et al. Measuring exposure to S. japonicum in China.: II. Activity diaries, pathways to infection and immunological correlates. Acta Trop. 1998;71:229-36.

68. Gazzinelli A, Hightower A, LoVerde PT, Haddad JPA, Pereira WR, Bethony J, et al. The spatial distribution of Schistosoma mansoni infection before and 
after chemotherapy in the Jequitinhonha Valley in Brazil. Mem Inst Oswaldo Cruz. 2006;101:63-71.

69. Kloos H, Rodrigues JCAP, Pereira WR, Velasquez-Melendez G, LoVerde P, Oliveira RC, et al. Combined methods for the study of water contact behavior in a rural schistosomiasis-endemic area in Brazil. Acta Trop. 2006;97:31-41.

70. Chandiwana SK, Woolhouse MEJ. Heterogeneities in water contact patterns and the epidemiology of Schistosoma haematobium. Parasitology. 1991;103:363-70

71. Kloos H, Gazzinelli A, Van Zuyle P. Microgeographical patterns of schistosomiasis and water contact behavior; examples from Africa and Brazil. Mem Inst Oswaldo Cruz. 1998;93:37-50.

72. Scott JT, Diakhate M, Vereecken K, Fall A, Diop M, Ly A, et al. Human water contacts patterns in Schistosoma mansoni epidemic foci in northern Senegal change according to age, sex and place of residence, but are not related to intensity of infection. Trop Med Int Health. 2003;8:100-8.

73. Rowan WB. Daily periodicity of Schistosoma mansoni cercariae in Puerto Rican waters. Am J Trop Med Hyg. 1958;7:374-81.

74. Kawashima K, Blas BL, Santos Jr AT. The cercarial emergence of Schistosoma japonicum from Oncomelania quadrasi under outdoor conditions in the Philippines. J Helminthol. 1985;59:225-31.

75. Ahmed AA, Ibrahim NA, Idris MA. Laboratory studies on the prevalence and cercarial rhythms of trematodes from Bulinus truncatus and Biomphalaria pfeifferi snails from Khartoum state, Sudan. Sultan Qaboos Univ Med J. 2006;6:65-9.

76. Hira PR. Seasonal population densities of snails transmitting urinary and intestinal schistosomiasis in Lusaka, Zambia. Trop Geogr Med. 1975;27:83-92.

77. Babiker A, Fenwick A, Daffalla AA, Amin MA. Focality and seasonality of Schistosoma mansoni transmission in the Gezira irrigated area, Sudan. J Trop Med Hyg. 1985:88:57-63.

78. Vera C, Bremond P, Labbo R, Mouchet F, Sellin E, Boulanger D, et al. Seasonal fluctuations in population densities of Bulinus senegalensis and B. truncatus (Planorbidae) in temporary pools in a focus of Schistosoma haematobium in Niger: implications for control. J Mollus Stud. 1995:61:79-88.

79. Muhoho ND, Katsumata T, Kimura E, Migwi DK, Mutua WR, Kiliku FM, et al. Cercarial density in the river of an endemic area of schistosomiasis haematobia in Kenya. Am J Trop Med Hyg. 1997;57:162-7.

80. Oliveira DS, Santos VB, Melo AG, Lima AS, Carvalho CD, Allegretti SM, et al. Schistosomiasis mansoni in urban northeast Brazil: influence of rainfall regime on the population dynamics of Biomphalaria sp. Rev Soc Bras Med Trop. 2013;46:654-7.

81. Tiglao TV, Camacho AC. Water contact behaviour among humans in Leyte, Philippines. Southeast Asian J Trop Med Public Health. 1983;14:18-24.

82. Jobin WR, Ruiz-Tiben E. Bilharzia and patterns of human contact with water in Puerto Rico. Bol Asoc Med Puert Rico. 1968;60:279-84.

83. Klumpp RK, Webbe G. Focal, seasonal and behavioural patterns of infection and transmission of Schistosoma haematobium in a farming village at the Volta Lake, Ghana. J Trop Med Hyg. 1987;90:265-81.

84. Ozumba NA, Christensen NO, Nwosu ABC, Nwaorgu OC. Endemicity, focality and seasonality of transmission of human schistosomiasis in Amagunze village, eastern Nigeria. J Helminthol. 1989;63:206-12.

85. Ndamkou NC, Ratard RC. Are sanitation, water supply and a health centre sufficient to control schistosomiasis? The case of Douloumi, north Cameroon. Trop Doct. 1990;20:176-7.

86. Muchiri EM, Ouma JH, King $\mathrm{CH}$. Dynamics and control of Schistosoma haematobium transmission in Kenya: an overview of the Msambweni project. Am J Trop Med Hyg. 1996;55:127-34.

87. Amazigo UO, Anago-Amanze $\mathrm{Cl}$, Okeibunor JC. Urinary schistosomiasis among school children in Nigeria: consequences of indigenous beliefs and water contact activities. J Biosoc Sci. 1997;29:9-18.

88. Ofoezie JE, Christensen NO, Madsen H. Water contact patterns and behavioural knowledge of schistosomiasis in south-west Nigeria. J Biosoc Sci. 1998:30:245-59.

89. Useh MF, Ejezie GC. Modification of behaviour and attitude in the control of schistosomiasis. 1. Observations on water-contact patterns and perception of infection. Ann Trop Med Parasitol. 1999;93:711-20.

90. Omonijo A, Asaolu S, Ofoezie I. Schistosomiasis transmission and water contact pattern in River Ureje in Ado-ekiti local government area, Ekiti state. Res J Parasitol. 2013;8:26-36.

91. Dalton PR. A socioecological approach to the control of Schistosoma mansoni in St Lucia. Bull World Health Organ. 1976;54:587-95.
92. Mafiana CF, Ekpo UF, Ojo DA. Urinary schistosomiasis in preschool children in settlements around Oyan Reservoir in Ogun State, Nigeria: implications for control. Trop Med Int Health. 2003;8:78-82.

93. Ekpo UF, Laja-Deile A, Oluwole AS, Sam-Wobo SO, Mafiana CF. Urinary schistosomiasis among preschool children in a rural community near Abeokuta. Nigeria Parasit Vectors. 2010;3:58.

94. Garba A, Barkire N, Djibo A, Lamine MS, Sofo B, Gouvras AN, et al. Schistosomiasis in infants and preschool-aged children: infection in a single Schistosoma haematobium and a mixed S. haematobium-S. mansoni foci of Niger. Acta Trop. 2010;115:212-9.

95. Ekpo UF, Alabi OM, Oluwole AS, Sam-Wobo SO. Schistosoma haematobium infections in preschool children from two rural communities in ljebu East, south-western Nigeria. J Helminthol. 2012;86:323-8.

96. Stothard JR, Sousa-Figueiredo JC, Betson M, Bustinduy A, Reinhard-Rupp J. Schistosomiasis in African infants and preschool children: let them now be treated! Trends Parasitol. 2013;29:197-205.

97. Poole H, Terlouw DJ, Naunje A, Mzembe K, Stanton M, Betson M, et al. Schistosomiasis in pre-school-age children and their mothers in Chikhwawa district, Malawi with notes on characterization of schistosomes and snails. Parasit Vectors. 2014;7:153.

98. Stephenson LS, Elliot TC, Kinoti SN. Water, sanitation and knowledge about urinary schistosomiasis in a Kenyan coastal community: a study combining ethnographic and survey techniques. In: Stephenson LS, editor. Schistosomiasis and Malnutrition. Ithaca: Cornell University, Division of Nutritional Sciences; 1986. p. 69-192.

99. Farooq M, Mallah MB. The behavioural pattern of social and religious water-contact activities in the Egypt-49 bilharziasis project area. Bull World Health Organ. 1966;35:377-87.

100. Teklehaimanot A, Fletcher M. A parasitological and malacological survey of schistosomiasis mansoni in the Beles Valley, northwestern Ethiopia. J Trop Med Hyg. 1990;93:12-21.

101. Akogun $O B$. Water demand and schistosomiasis among the Gumau people of Bauchi state, Nigeria. Trans R Soc Trop Med Hyg. 1990;84:548-50.

102. Tameim O, Daffala AAR, Babbiker Mohamed A, Abdel Basit S, El Gaddal AA, Fenwick A, et al. Water supply systems in Blue Nile Health Project. J Environ Eng. 1987;116:1219-33.

103. Pitchford RJ. Findings in relation to schistosome transmission in the field following the introduction of various control measures. S Afr Med J. 1966;40 Suppl 40:41-16.

104. Pitchford RJ. Control of bilharziasis by rural management. Cent Afr J Med. 1970;16 Suppl:31-3.

105. Pitchford RJ. Further observations on bilharzia control in the Eastern Transvaal. S Afr Med J. 1970:44:475-7.

106. Jordan P, Woodstock L, Unrau GO, Cook JA. Control of Schistosoma mansoni transmission by provision of domestic water supplies. A preliminary report of a study in St Lucia. Bull World Health Organ. 1975;52:9-20.

107. Jordan P. Schistosomiasis-research to control. Am J Trop Med Hyg. 1977;26:877-86.

108. Jordan P, Bartholomew RK, Unrau GO. Further observations from St Lucia on control of Schistosoma mansoni transmission by provision of domestic water supplies. Bull World Health Organ. 1978;56:965-73.

109. Jordan P. Schistosomiasis can be prevented. World Health Forum. 1988;9:104-6.

110. Kosinski KC, Crocker JJ, Durant JL, Osabutey D, Adjei MN, Gute DM. A novel community-based water recreation area for schistosomiasis control in rural Ghana. J Wat San Hyg Dev. 2011;1:259-68.

111. Kosinski KC, Adjei MN, Bosompem KM, Crocker JJ, Durant JL, Osabutey D, et al. Effective control of Schistosoma haematobium infection in a Ghanaian community following installation of a water recreation area. PLoS Negl Trop Dis. 2012;6:e1709.

112. Taylor P, Chandiwana SK, Govere JM, Chombo F. Knowledge attitudes and practices in relation to schistosomiasis in a rural community. Soc Sci Med. 1987;24:607-11.

113. Noda S, Shimada M, Muhoho ND, Sato K, Kiliku FBM, Gatika SM, et al. Effect of piped water supply on human water contact patterns in a Schistosoma haematobium-endemic area in Coast province, Kenya. Am J Trop Med Hyg. 1997;56:118-26.

114. Ndassa A, Mimpfoundi R, Gake B, Martin MVP, Poste B. Risk factors for human schistosomiasis in the Upper Benue valley, in northern Cameroon. Ann Trop Med Parasitol. 2007;101:469-77.

115. Kloos H, Lemma A, Kirub B. Intestinal parasitism in migrant farm labour populations in irrigation schemes in the Awash Valley, Ethiopia, and in major labour source areas. Ethiop Med J. 1980;18:53-62. 
116. El Kholy H, Arap Siongok TK, Koech D, Sturrock RF, Houser $H$, King CH, et al. Effects of borehole wells on water utilization in Schistosoma haematobium endemic communities in Coast province, Kenya. Am J Trop Med Hyg. 1989:41:212-9.

117. Loroni-Lakwo T, Odongo-Aginya El, Schweigmann U, Schickerling S, Lindner D, Doehring-Schwerdtfeger E. Transmission of Schistosoma mansoni in Rhino Camp, Uganda. East Afr Med J. 1994;71:165-6.

118. Mehanna S, Rizkalla NH, Elsayed HF, Winch PJ. Social and economic conditions in two newly reclaimed areas in Egypt: implications for schistosomiasis control strategies. J Trop Med Hyg. 1994;97:286-97.

119. Gazzinelli A, Gazzinelli MF, Cadete MM, Pena Filho S, Sa IR, Kloos H. Sociocultural aspects of schistosomiasis mansoni in an endemic area in Minas Gerais, Brazil. Cad Saude Publica. 1998;14:841-9.

120. Acka CA, Raso G, N'Goran EK, Tschannen AB, Bogoch II, Seraphin E, et al. Parasitic worms: knowledge, attitudes, and practices in western Côte d'lvoire with implications for integrated control. PLoS Negl Trop Dis. 2010;4:e910.

121. Katsivo MN, Muthami LN, Karama M, Kingori F. Perception of a schistosomiasis control project in rural Kenya by the beneficiaries. East Afr Med J. 1993;70:613-6.

122. Chimbari M, Ndlela B, Nyati Z, Thomson A, Chandiwana SK, Bolton P. Bilharzia in a small irrigation community: an assessment of water and toilet usage. Cent Afr J Med. 1992;38:451-8.

123. Gwatirisa PR, Ndamba J, Nyazema NZ. The impact of health education on the knowledge, attitudes and practices of a rural community with regards to schistosomiasis control using a plant molluscicide, Phytolacca dodecandra. Cent Afr J Med. 1999;45:94-7.

124. Appleton CC, Bruton MN. The epidemiology of schistosomiasis in the vicinity of Lake Sibaya, with a note on other areas of Tongaland (Natal, South Africa). Ann Trop Med Parasitol. 1979;73:547-61.

125. Pinot de Moira A, Kabatereine NB, Dunne DW, Booth M. Understanding ethnic differences in behaviour relating to Schistosoma mansoni re-infection after mass treatment. J Biosoc Sci. 2011;43:185-209.

126. Sturrock RF. The control of schistosomiasis: epidemiological aspects of reinfection. Mem Inst Oswaldo Cruz. 1989;84 Suppl 1:134-48.

127. Wilkins HA, Goll PH, Marshall TF, Moore PJ. Dynamics of Schistosoma haematobium infection in a Gambian community. I. The pattern of human infection in the study area. Trans R Soc Trop Med Hyg. 1984;78:216-21.

128. Anderson RM. Determinants of infection in human schistosomiasis. Baillières Clin Trop Med Comm Dis. 1987;2:279-300.

129. Seto EYW, Lee YJ, Liang S, Zhong B. Individual and village-level study of water contact patterns and Schistosoma japonicum infection in mountainous rural China. Trop Med Int Health. 2007;12:1199-209.

130. Fulford AJC, Webster M, Ouma JH, Kimani G, Dunne DW. Puberty and age-related changes in susceptibility to schistosome infection. Parasito Today. 1998;14:23-6.

131. Jordan P. Epidemiology and control of schistosomiasis. Br Med Bull. 1972;28:55-9.

132. Dalton PR, Pole D. Water-contact patterns in relation to Schistosoma haematobium infection. Bull World Health Organ. 1978;56:417-26.

133. Kvalsvig JD, Schutte CHJ. The role of human water contact patterns in the transmission of schistosomiasis in an informal settlement near a major industrial area. Ann Trop Med Parasitol. 1986;80:13-26.

134. Mota E, Sleigh AC. Water-contact patterns and Schistosoma mansoni infection in a rural community in northeast Brazil. Rev Inst Med Trop Sao Paulo. 1987;29:1-8

135. Kloos H, Higashi G, Schinski VD, Mansour NS, Murrell KD, Miller FD. Water contact and Schistosoma haematobium infection: a case study from an upper Egyptian village. Int J Epidemiol. 1990;19:749-58.

136. Zhou H, Ross AG, Hartel GF, Sleigh AC, Williams GM, McManus DP, et al. Diagnosis of schistosomiasis japonica in Chinese schoolchildren by administration of a questionnaire. Trans R Soc Trop Med Hyg. 1998;92:245-50.

137. Utzinger J, N'Goran EK, Tanner M, Lengeler C. Simple anamnestic questions and recalled water-contact patterns for self-diagnosis of Schistosoma mansoni infection among schoolchildren in western Côte d'Ivoire. Am J Trop Med Hyg. 2000;62:649-55.

138. Ximenes R, Southgate B, Smith PG, Guimaraes Neto L. Socioeconomic determinants of schistosomiasis in an urban area in the northeast of Brazil. Rev Panam Salud Publica. 2003;14:409-21.

139. Tukahebwa EM, Magnussen $P$, Madsen $H$, Kabatereine NB, Nuwaha F, Wilson $S$, et al. A very high infection intensity of Schistosoma mansoni in a Ugandan Lake Victoria fishing community is required for association with highly prevalent organ related morbidity. PLoS Negl Trop Dis. 2013;7:e2268.
140. Seto EYW, Sousa-Figueiredo JC, Betson M, Byalero C, Kabatereine NB, Stothard JR. Patterns of intestinal schistosomiasis among mothers and young children from Lake Albert, Uganda: water contact and social networks inferred from wearable global positioning system dataloggers. Geospat Health. 2013;7:1-13.

141. Polderman AM. The transmission of intestinal schistosomiasis in Begemder Province, Ethiopia. Acta Leiden. 1975:42:1-193.

142. Polderman AM. Transmission dynamics of endemic schistosomiasis. Trop Geogr Med. 1979;31:465-75.

143. Wilkins HA, Goll PH, Marshall TF, Moore PJ. Dynamics of Schistosoma haematobium infection in a Gambian community. III. Acquisition and loss of infection. Trans R Soc Trop Med Hyg. 1984;78:227-32.

144. Barbour AD. The importance of age and water contact patterns in relation to Schistosoma haematobium infection. Trans R Soc Trop Med Hyg. 1985;79:151-3.

145. Chandiwana SK. Community water-contact patterns and the transmission of Schistosoma haematobium in the highveld region of Zimbabwe. Soc Sci Med. 1987;25:495-505.

146. Etard JF, Audibert M, Dabo A. Age-acquired resistance and predisposition to reinfection with Schistosoma haematobium after treatment with praziquantel in Mali. Am J Trop Med Hyg. 1995;52:549-58.

147. Kabatereine NB, Vennervald BJ, Ouma JH, Kemijumbi J, Butterworth AE, Dunne DW, et al. Adult resistance to schistosomiasis mansoni: age dependence of reinfection remains constant in communities with diverse exposure patterns. Parasitology. 1999;118:101-5.

148. King $\mathrm{CH}$. Long-term outcomes of school-based treatment for control of urinary schistosomiasis: a review of experience in Coast province, Kenya. Mem Inst Oswaldo Cruz. 2006;101 Suppl 1:299-306.

149. Woolhouse MEJ, Mutapi F, Ndhlovu PD, Chandiwana SK, Hagan P. Exposure, infection and immune responses to Schistosoma haematobium in young children. Parasitology. 2000;120:37-44.

150. Maldonado JF, Acosta-Matienzo J. Biological studies on the miracidium of Schistosoma mansoni. I. Hatchability, longevity, and infectivity of the miracidium of Schistosoma mansoni. Am J Trop Med Hyg. 1948;28:645-57.

151. Maldonado JF, Acosta Matienzo J, Thillet CJ. Biological studies on the miracidium of Schistosoma mansoni. II. Behaviour of the unhatched miracidium in undiluted stools under diverse environmental conditions. Puert Rico J Public Health Trop Med. 1949;25:153-99.

152. Kawata $\mathrm{K}$, Kruse CW. The effect of sewage stabilization ponds on the eggs and miracidia of Schistosoma mansoni. Am J Trop Med Hyg. 1966;15:896-901.

153. Remais J, Chen $L$, Seto E. Leveraging rural energy investment for parasitic disease control: schistosome ova inactivation and energy co-benefits of anaerobic digesters in rural China. PLoS One. 2009;4:e4856.

154. Brown HW. Studies on the rate of development and viability of the eggs of Ascaris lumbricoides and Trichuris trichiura under field conditions. J Parasitol. 1927:14:1-15.

155. Brown HW. Further studies on the longevity of the eggs of Ascaris lumbricoides and A. suum. J Parasitol. 1928;15:14-22.

156. Enk MJ, Lima ACL, Barros HD, Massara CL, Coelho PMZ, Schall VT. Factors related to transmission of and infection with Schistosoma mansoni in a village in the south-eastern region of Brazil. Mem Inst Oswaldo Cruz. 2010;105:570-7.

157. Jordan P, Christie JD, Unrau GO. Schistosomiasis transmission with particular reference to possible ecological and biological methods of control. A review Acta Trop. 1980;37:95-135.

158. Chandiwana SK. How Schistosoma mansoni eggs reach natural waterbodies. Trans R Soc Trop Med Hyg. 1986;80:963-4.

159. Cheesmond AK, Fenwick A. Human excretion behaviour in a schistosomiasis endemic area of the Geizira, Sudan. J Trop Med Hyg. 1981;84:101-7.

160. Fenwick A, Cheesmond AK, Kardaman M, Amin MA, Manjing BK. Schistosomiasis among labouring communities in the Gezira irrigated area, Sudan. J Trop Med Hyg. 1982;85:3-11.

161. Akogun OB, Akogun MK. Human behaviour, water usage and schistosomiasis transmission in a small settlement near Yola, Nigeria. Ann Trop Med Parasitol. 1996;90:303-11.

162. Sow S, de Vlas SJ, Polman K, Gryseels B. [Hygiene practices and contamination risks of surface waters by schistosome eggs: the case of an infested village in Northern Senegal]. Bull Soc Pathol Exot. 2004:97:12-4 (in French).

163. Kloos H, Lemma A. The epidemiology of Schistosoma mansoni infection in Tensae Berhan: human water contact patterns. Ethiop Med J. 1980;18:91-8.

164. Feachem RG, Bradley DJ, Garelick H, Mara DD. Sanitation and disease: health aspects of excreta and wastewater management. In: World Bank studies in water supply and sanitation, vol. 3. New York, NY: John Wiley \& Sons; 1983. 
165. Husting EL. Sociological patterns and their influence on the transmission of bilharziasis. Cent Afr J Med. 1970;16 Suppl:5-10.

166. Rollinson D, Knopp S, Levitz S, Stothard JR, Tchuem Tchuenté LA, Garba A, et al. Time to set the agenda for schistosomiasis elimination. Acta Trop. 2013;128:423-40.

167. Cheng T. Schistosomiasis in mainland China: a review of research and control programs since 1949. Am J Trop Med Hyg. 1971;20:26-53.

168. Wu HW, Qin YF, Chu K, Meng R, Liu Y, McGarvey ST, et al. High prevalence of Schistosoma japonicum infection in water buffaloes in the Philippines assessed by real-time polymerase chain reaction. Am J Trop Med Hyg. 2010;82:646-52.

169. Gordon CA, Acosta LP, Gray DJ, Olveda RM, Jarilla B, Gobert GN, et al. High prevalence of Schistosoma japonicum infection in carabao from Samar province, the Philippines: implications for transmission and control. PLoS Negl Trop Dis. 2012;6:e1778.

170. Wang TP, Johansen MV, Zhang SQ, Wang FF, Wu WD, Zhang GH, et al. Transmission of Schistosoma japonicum by humans and domestic animals in the Yangtze River valley, Anhui province, China. Acta Trop. 2005;96:198-204.

171. Gray DJ, Williams GM, Li YS, Chen HG, Forsyth SJ, Li RS, et al. A cluster-randomised intervention trial against Schistosoma japonicum in the People's Republic of China: bovine and human transmission. PLoS One. 2009:4:e5900.

172. Wang TP, Wang FF, Zhu L, Zhang SQ, Ørnbjerg N, Johansen MV. Schistosoma japonicum eggs survive passage through dogs and chickens. Vet Parasitol. 2006;140:362-5.

173. Fenwick A. Baboons as reservoir hosts of Schistosoma mansoni. Trans R Soc Trop Med Hyg. 1969;63:557-67.

174. Muller-Graf CD, Collins DA, Packer C, Woolhouse MEJ. Schistosoma mansoni infection in a natural population of olive baboons (Papio cynocephalus anubis) in Gombe Stream National Park, Tanzania. Parasitology. 1997;115:621-7.

175. Erko B, Gebre-Michael T, Balcha F, Gundersen SG. Implication of Papio anubis in the transmission of intestinal schistosomiasis in three new foci in Kime area, Ethiopia. Parasitol Int. 2001;50:259-66.

176. Legesse M, Erko B. Zoonotic intestinal parasites in Papio anubis (baboon) and Cercopithecus aethiops (vervet) from four localities in Ethiopia. Acta Trop. 2004;90:231-6.

177. Stothard JR, Mugisha L, Standley CJ. Stopping schistosomes from 'monkeying-around' in chimpanzees. Trends Parasitol. 2012;28:320-6.

178. Rioux JA, Decamps H, Lanotte G. Ecology of intestinal schistosomiasis in Guadeloupe. Epidemiological analysis and data for a model study. Rev Epidemiol Sante. 1977;25:483-519 (in French).

179. Karoum KO, Amin MA. Domestic and wild animals naturally infected with Schistosoma mansoni in the Gezira irrigated scheme, Sudan. J Trop Med Hyg. 1985;88:83-9.

180. Silva TMC, Andrade ZA. [Natural infection of wild rodents by Schistosoma mansoni]. Mem Inst Oswaldo Cruz. 1989:84:227-35 (in Portuguese).

181. D'Andrea PS, Maroja LS, Gentile R, Cerqueira R, Maldonado Jr A, Rey L. The parasitism of Schistosoma mansoni (Digenea-Trematoda) in a naturally infected population of water rats, Nectomys squamipes (Rodentia-Sigmodontinae) in Brazil. Parasitology. 2000;120:573-82.

182. D'Andrea PS, Fernandes FA, Cerqueira R, Rey L. Experimental evidence and ecological perspectives for the adaptation of Schistosoma mansoni Sambon, 1907 (Digenea: Schistosomatidae) to a wild host, the water-rat, Nectomys squamipes Brants, 1827 (Rodentia: Sigmodontinae). Mem Inst Oswaldo Cruz. 2002:97 Suppl 1:11-4.

183. Gentile R, Costa-Neto SF, Goncalves MML, Bonecker ST, Fernandes FA, Garcia $J$, et al. An ecological field study of the water-rat Nectomys squamipes as a wild reservoir indicator of Schistosoma mansoni transmission in an endemic area. Mem Inst Oswaldo Cruz. 2006;101 Suppl 1:111-7.

184. Maldonado Jr A, Gentile R, Fernandes-Moraes CC, D'Andrea PS, Lanfredi RM, Rey L. Helminth communities of Nectomys squamipes naturally infected by the exotic trematode Schistosoma mansoni in southeastern Brazil. J Helminthol. 2006:80:369-75.

185. Nithiuthai S, Anantaphruti MT, Waikagul J, Gajadhar A. Waterborne zoonotic helminthiases. Vet Parasitol. 2004;126:167-93.

186. Macdonald G. The dynamics of helminth infections, with special reference to schistosomes. Trans R Soc Trop Med Hyg. 1965;59:489-506.

187. Nåsell I. On transmission and control of schistosomiasis, with comments on Macdonald's model. Theor Popul Biol. 1977;12:335-65.

188. Goddard MJ. On Macdonald's model for schistosomiasis. Trans R Soc Trop Med Hyg. 1978;72:123-31.
189. El-Gindy MS. Incidence of Schistosoma mansoni in the vector snail, Planorbis boissyi. J Egypt Med Assoc. 1954;37:1259-71.

190. El-Gindy MS. Distribution and ecology of the snail vectors of schistosomiasis in Egypt. J Egypt Med Assoc. 1957;40:192-204.

191. Alves W. Chemical constituents of surface water in Southern Rhodesia, with special reference to the molluscan vectors of bilharziasis. Bull World Health Organ. 1958;18:1071.

192. Bruijning CF. Bilharziasis in irrigation schemes in Ethiopia. Trop Geogr Med. 1969;21:280-92.

193. Garcia RG. Tolerance of Oncomelania hupensis quadrasi to varying concentrations of dissolved oxygen and organic pollution. Bull World Health Organ. 1972;47:59-70.

194. Klutse A, Baleux B. [Survival of Bulinus truncatus and Biomphalaria pfeifferi in sewer water purified in stabilization ponds in a Sudanese-Saharan zone]. Med Trop (Mars). 1996:56:41-7 (in French).

195. Gazzinelli MFC, Kloos H, de Cassia MR, dos Reis DC, Gazzinelli A. Popular beliefs about the infectivity of water among school children in two hyperendemic schistosomiasis areas of Brazil. Acta Trop. 2008;108:202-8.

196. Anderson RM, Mercer JG, Wilson RA, Carter NP. Transmission of Schistosoma mansoni from man to snail: experimental studies of miracidial survival and infectivity in relation to larval age, water temperature, host size and host age. Parasitology. 1982;85:339-60.

197. Pesigan T, Hairston N, Jauregui J, Garcia E, Santos A, Santos B, et al. Studies on Schistosoma japonicum infection in the Philippines: 2. The molluscan host. Bull World Health Organ. 1958;18:481-578.

198. Pan CT. Studies on the host-parasite relationship between Schistosoma mansoni and the snail Australorbis glabratus. Am J Trop Med Hyg. 1965:14:931-76.

199. Webbe G. Transmission of bilharziasis. 2. Production of cercariae. Bull World Health Organ. 1965:33:155-62.

200. Anderson RM, May RM. Prevalence of schistosome infections within molluscan populations: observed patterns and theoretical predictions. Parasitology. 1979;79:63-94

201. Webbe G, James C. Host-parasite relationships of Bulinus globosus and B. truncatus with strains of Schistosoma haematobium. J Helminthol. 1972;46:185-99.

202. Mangal TD, Paterson S, Fenton A. Predicting the impact of long-term temperature changes on the epidemiology and control of schistosomiasis: a mechanistic model. PLoS One. 2008:3:e1438.

203. Sandbach FR. Preventing schistosomiasis: a critical assessment of present policy. Soc Sci Med. 1975;9:517-27.

204. Ling B, Den TX, Lu ZP, Min LW, Wang ZX, Yuan AX. Use of night soil in agriculture and fish farming. World Health Forum. 1993;14:67-70.

205. Carlton EJ, Liu Y, Zhong B, Hubbard A, Spear RC. Associations between schistosomiasis and the use of human waste as an agricultural fertilizer in China. PLoS Negl Trop Dis. 2015;9:e3444.

206. Pacheco G, Jansen J. [Destruction of Schistosoma mansoni cercariae with soaps combined with dyes]. Bras Med. 1951;65:301-4 (in Portuguese).

207. Mimpfoundi R, Dupouy J. [Action of various detergents in use in Cameroon on the vitality of Schistosoma mansoni cercariae: influence of the hardness factor of water]. C R Seances Soc Biol Fil. 1983;177:338-46 (in French).

208. van Rensburg LJ. Protective action of a liquid soap against bilharzia. J S Afr Vet Med Assoc. 1972;43:405-7.

209. van Emden HM, Kroon CCM, Schoeman EN, Van Seventer HA. The toxicity of some detergents tested on Aedes aegypti L., Lebistes reticulatus Peters, and Biomphalaria glabrata (Say). Environ Pollut. 1974;6:297-308.

210. Esser KB, Semagn K, Wolde-Yohannes L. Medicinal use and social status of the soap berry endod (Phytolacca dodecandra) in Ethiopia. J Ethnopharmacol. 2003;85:269-77.

211. Lemma A. Laboratory and field evaluation of the molluscicidal properties of Phytolacca dodecandra. Bull World Health Organ. 1970;42:597-612.

212. Madhina D, Shiff C. Prevention of snail miracidia interactions using Phytolacca dodecandra (L'Herit) (endod) as a miracidiacide: an alternative approach to the focal control of schistosomiasis. Trop Med Int Health. 1996;1:221-6.

213. Abebe F, Erko B, Gemetchu T, Gundersen SG. Control of Biomphalaria pfeifferi population and schistosomiasis transmission in Ethiopia using the soap berry endod (Phytolacca dodecandra), with special emphasis on application methods. Trans R Soc Trop Med Hyg. 2005;99:787-94.

214. Wilkins HA, Blumenthal UJ, Hagan P, Hayes RJ, Tulloch S. Resistance to reinfection after treatment of urinary schistosomiasis. Trans R Soc Trop Med Hyg. 1987;81:29-35. 
215. Rudge JW, Stothard JR, Basáñez MG, Mgeni AF, Khamis IS, Khamis AN, et al. Micro-epidemiology of urinary schistosomiasis in Zanzibar: local risk factors associated with distribution of infections among schoolchildren and relevance for control. Acta Trop. 2008;105:45-54

216. Sow S, de Vlas SJ, Stelma F, Vereecken K, Gryseels B, Polman K. The contribution of water contact behavior to the high Schistosoma mansoni infection rates observed in the Senegal River Basin. BMC Infect Dis. 2011;11:198.

217. Erko B, Abebe F, Berhe N, Medhin G, Gebre-Michael T, Gemetchu T, et al. Control of Schistosoma mansoni by the soapberry endod (Phytolacca dodecandra) in Wollo, northeastern Ethiopia: post-intervention prevalence. East Afr Med J. 2002;79:198-201.

218. Esrey SA, Potash JB, Roberts L, Shiff C. Effects of improved water supply and sanitation on ascariasis, diarrhoea, dracunculiasis, hookworm infection, schistosomiasis, and trachoma. Bull World Health Organ. 1991;69:609-21.

219. Fenwick A, Webster JP, Bosque-Oliva E, Blair L, Fleming FM, Zhang Y, et al. The Schistosomiasis Control Initiative (SCl): rationale, development and implementation from 2002-2008. Parasitology. 2009;136:1719-30.

\section{Submit your next manuscript to BioMed Central and take full advantage of:}

- Convenient online submission

- Thorough peer review

- No space constraints or color figure charges

- Immediate publication on acceptance

- Inclusion in PubMed, CAS, Scopus and Google Scholar

- Research which is freely available for redistribution 